Resenha

MATAREZIO FILHO, Edson Tosta. Ritual e Pessoa entre os Wamiri-Atroari.

São Paulo, Annablume, 2014, 266 pp.

\title{
Um estudo da construção da pessoa waimiri-atroari: entre temas clássicos e novas comparações
}

Eduardo Santos Gonçalves Monteiro

Universidade de São Paulo

Resultado de uma dissertação em antropologia realizada na Universidade de São Paulo, Ritual e Pessoa entre os Waimiri-Atroari, como o título desvela, relaciona duas questões clássicas da etnologia, a noção de pessoa e de ritual, mais especificamente o ritual de iniciação masculina entre os Waimiri Atroari, babinja maryba. Trata-se de uma síntese bibliográfica que promove a aliança entre séries de dados etnográficos sobre povos indígenas sul-americanos e informações obtidas em algumas conversas e sessões de vídeos de rituais acompanhadas por lideranças waimiri-atroari na sede do Programa Waimiri-Atroari (PWA ${ }^{1}$, onde Matarezio pesquisou durante sua estadia de dois meses em Manaus, em 2009, e as quais se mostraram, segundo o autor, extremamente valiosas para o trabalho final que chega ao leitor.

Como Márnio Teixeira-Pinto já antecipa em seu prefácio, o livro realiza um exercício de produção de articulações entre problemas e modelos analíticos de grande embocadura e especificidades etnográficas, buscando promover uma elucidação recíproca de ambos os planos. Em momento algum Matarezio se restringe a uma visão centrada exclusivamente no material waimiri-atroari; ao contrário, parece-nos que a aposta é justamente iluminá-lo através da abertura à comparação constante, em planos e escalas variadas, ainda que centrados em sua maior parte em informações etnográficas de outros grupos guianenses. Estão entre estes os Piaroa, Pemon, Trio, Aparai e Wayana, mas 
também, lista Teixeira-Pinto, “os Tupinambá históricos da costa brasileira e os Arara atuais do Pará, os Ticuna do Alto Solimões, e os Kalapalo do Alto Xingu, os Marubo do Vale do Javari e os Bakairi do interflúvio Tapájos-Xingu, os Kashinawa do Acre e os Toba do Chaco argentino" (:16). Ao mesmo tempo, esta predisposição dialógica do livro se realiza em nível teórico: cria-se uma ponte, assim, entre a "evocação melanésia subjacente" ao livro, que enfatiza caráter relacional e fractal da pessoa waimiri-atroari, e questões centrais para a etnologia americanista recente - sobretudo, "o lugar da afinidade e da exterioridade na Amazônia indígena, o perspectivismo ameríndio" (:15). Acompanhemos, então, o desenvolvimento da obra, atentando para seus aspectos e argumentos principais na medida em que são evocados, capítulo a capítulo.

$\mathrm{Na}$ curta introdução do livro, Matarezio descreve o processo de delimitação do campo de pesquisa e decisão entre certas opções temáticas e metodológicas; detalha suas condições de pesquisa, sobretudo em relação às conversas com as lideranças waimiri-atroari; delineia uma imagem panorâmica dos argumentos e seções do livro, dividido em 3 capítulos e considerações finais; e apresenta a trajetória e os argumentos que o impeliram à escolha de seu principal objeto de pesquisa, o maryba babinja. Neste sentido, o autor menciona a importância da mudança de classe pela qual passam os iniciandos do ritual: trata-se de uma nova categoria de pessoa, bahinja-tahapa, oposta a todas categorias anteriores, que rompe drasticamente com a vida infantil e torna o neófito um "caçador casadouro" que deve passar a acompanhar os pais para "começar a aprender" (:22). Além disso, a própria ocasião da festa mostra-se indispensável para a dinâmica da socialidade waimiri-atroari: "nas maryba, os arranjos matrimoniais são traçados para os solteiros e viúvos, a afinidade é atualizada, e as alianças políticas reiteradas" (idem); rearranjos do parentesco são operados, pessoas são fabricadas. E é justamente esta fabricação de pessoas a preocupação central de nosso autor durante o livro. Como afirma Matarezio, fortemente inspirado pelo trabalho de Eduardo Viveiros de Castro,

o problema da pesquisa [..] é investigar uma determinada noção de pessoa produ₹ida durante este ritual, ou, em outros termos, como são produðidos os verdadeiros homens kinja. Uma posição ou perspectiva que - como mostram os mitos, pode ser perdida - durante o ritual é atualizada. Para tornar-se parte do "nós", para tornar-se um consanguíneo, o menino deve ser fabricado enquanto tal, sendo que a contrapartida desta fabricação é a "contra-invenção" da afinidade. (:26) 
O capítulo 1 procura apresentar um panorama geral dos Waimiri-Atroari, que correspondem a cerca de 1.300 falantes de língua do tronco Caribe, localizados entre os estados do Amazonas e Roraima (:29). Sendo o capítulo mais breve do livro, ressalta uma série de informações demográficas, geográficas e sobretudo históricas a respeito destes indígenas e apresenta ao leitor o desenvolvimento processual, extremamente delicado e complexo, das relações estabelecidas com os kaminja, os brancos ou "civilizados", desde o século XIX, processo este compartilhado parcialmente - em especial no que diz respeito ao seu caráter violento - pela maior parte dos ameríndios. "Um caso extremo, mas longe de ser incomum, da danosa realidade de colonialismo interno, estatal e econômico, de que são vítimas vários povos indígenas no Brasil”, como afirma Teixeira-Pinto em seu prefácio (:18). Assim, e sem conexões explícitas com a análise dos capítulos seguintes, relata-se um histórico conflituoso, um estado de guerra permanente entre índios e brancos na região do baixo Rio Negro (:33), nutrido pelas atitudes exterminadoras das expedições dos brancos e marcado por alternâncias entre eventos atrozes, períodos de longo isolamento indígena, concessões e revogações de direitos.

O caráter da relação com entidades estatais oscilava entre medidas integracionistas, conforme o ideário defendido por Rondon, nas quais o "contato pacífico" através do Serviço de Proteção ao Índio (SPI) permitiria uma assimilação do indígena à sociedade nacional como trabalhador produtivo, e a absoluta negligência que abria espaço para a invasão de gateiros e exploradores particulares de castanhais, resultando quase invariavelmente em massacres e apropriações indevidas das terras indígenas. O processo de construção da BR-174, iniciado em 1968, é emblemático: atravessando violentamente o território waimiri-atroari, reduz a um sétimo a população inicial, promove violentos ataques às lideranças resistentes à construção e, após finalmente terminado em 1977, propicia a emergência de projetos hidrelétricos, agropecuários e de mineração na região.

Após este breve panorama histórico, somos encaminhados para o cerne do argumento do livro, explorado nos capítulos 2 e 3. O segundo, Os Kinja e seus Outros, é construído em função do capítulo seguinte, onde se encontra a descrição do ritual propriamente, e busca fornecer os instrumentos necessários para que a análise deste último possa ser efetivamente acompanhada pelo leitor. Para tanto, Matarezio recorre a inúmeras categorias sociais centrais para os Waimiri-Atroari, lançando mão de um exercício comparativo com o material etnográfico sobre outros grupos indígenas da região guianense. Assim, o segundo capítulo tem início com uma discussão sobre uma teoria nativa da troca e a relação entre afins. Nele, apoiado nos resultados da dissertação de 
Luciana França (UFRJ), Matarezio retoma criticamente o modelo guianense proposto por Peter Rivière, construído, nas palavras do primeiro, a partir de uma ideia de "sociedade como um todo que comporta suas partes, os indivíduos, concebidos a priori, articulando suas relações sociais extrínsecas" (:57). Neste modelo, a relação hierarquizante entre sogro e genro comportaria um "dispositivo de totalização do socius": a partir do controle parcial do primeiro pelo segundo mediado pela submissão das filhas deste, a produção da sociedade seria resultado das negociações entre indivíduos na alocação de recursos escassos, as pessoas.

A partir da análise de França de narrativas pemon, trio e piaroa sobre a relação entre sogro e genro, a qual evidencia uma socialidade fundada na predação e no canibalismo, Matarezio busca compreender a mesma relação no mito waimiri-atroari do Xiriminja, cobra-grande que, assim como o papagaio, doou sua filha ao primeiro homem tabkome para que fosse sua mulher. Afastando-se das ideias de indivíduo e controle presente no modelo de Rivière e inspirado pelo aspecto perspectivista do pensamento ameríndio e pela ideia de fractalização, ele enfatiza a alternância contextual entre "qualidade-de-sujeito" e "qualidade-de-objeto", inerente à pessoa waimiri-atroari e aos seres presentes nos mitos. Esta mudança de perspectiva não resulta jamais na perda completa da qualidade em segundo plano; pelo contrário, é justamente esta capacidade de deslocamento que torna a operação de troca valiosa e produtiva - pois se trata de mitos da "origem" de bens culturais, detidos pelos sogros não-humanos.

Durante sua incursão às narrativas míticas, o termo kinja mostra-se fundamental, indicando "que o agente no mito tem sua qualidade-de-sujeito alçada ao primeiro plano" (:64). Por sua importância aqui e, em termos gerais, para o entendimento das classificações sociais dos Waimiri-Atroari e da análise do ritual por vir, Matarezio detém-se sobre o termo de forma mais detalhada, reunindo seus múltiplos sentidos contextuais ao mesmo tempo em que acompanha o uso de certos sufixos que indicam qualidades atribuídas a sujeitos, como o sufixo - $e^{\prime} m e$. As conclusões do exercício são bem enunciadas em suas próprias palavras:

Em suma, alinhando-se a um conjunto de povos ameríndios que utilizam como categoria de identidade coletiva o que Viveiros de Castro chamou "pronomes cosmológicos", os Waimiri-Atroari utilizam a palavra kinje'me para indicar que o agente que está contagiado por este afeto agirá e se apreenderá como um kinja, isto é, como gente, uma pessoa, com "as capacidades de intencionalidade consciente e de agência que definem a posição de sujeito" 
(1996:126), além de forma corporal humana e cultura. Enfim, kinje'me indica a "condição social de pessoa" (idem:125). (p.76)

Estar agenciado sobre a perspectiva kinja requer forçosamente, portanto, a manifestação de certas qualidades e práticas: "alimentar-se de mingau de banana e outras 'comidas de gente' (kinja ipa), cantar maryba durante as festas, casar-se com kinja, acatar as interdições alimentares, falar língua de gente (kinja iara)" (ibidem).

Após uma apresentação sucinta de resultados obtidos através de uma aliança ainda pouco explorada mas repleta de potencialidades entre os estudos de parentescos e análises computacionais - na esteira das pesquisas feitas por seu orientador, Márcio Ferreira da Silva -, Matarezio continua a análise de certas categorias de alteridade waimiri-atroari. A partir daqui, fica ainda mais evidente o já mencionado recurso à comparação etnográfica: mobiliza-se sistematicamente uma série de materiais guianenses, distribuindo-os em torno e em relação às informações sobre os Waimiri-Atroari. Ao explicitar certas aproximações, afastamentos e inversões entre os casos, um grupo de transformações vai tomando forma em seu trabalho, e neste sentido poderíamos mesmo dizer que a leitura do capítulo pode ser pensada como via de acesso introdutória a uma série de questões caras aos grupos guianenses.

Mas voltemos ao percurso do livro. Em diálogo com as ideias de Joanna Overing a respeito da "filosofia social" compartilhada pelos povos ameríndios, segundo a qual existência do cosmos e da vida social está subordinada à mistura adequada entre elementos diferentes entre si e potencialmente perigosos, Matarezio apresenta a primeira categoria de afinidade analisada, yaska. Este termo corresponde à maneira waimiri-atroari de realizar um “equacionamento da co-residência e da consanguinidade" (:88), operação cara à socialidade guianense e sublinhada por Overing.

Se yaska corresponde a uma "espécie de 'categoria nativa' que circunscreve o âmbito do parentesco" (idem), ela se mostra importante para o entendimento do bahinja maryba por adquirir neste contexto ritual "o sentido metafórico de consanguinidade", cristalizando o grupo de anfitriões consanguíneos yaska que receberão os paxira: parceiros rituais, afins, e segunda categoria analisada na seção. Aproximando-a aos cognatos pawana, praticamente onipresentes entre os povos de língua Caribe, o autor avalia as variações de sentido do termo paxira e faz coro à afirmação de Catherine Howard, que observa uma referência comum às relações de afinidade ou modeladas na afinidade que todos os cognatos pawana parecem possuir. Com isso Matarezio não pretende reduzir a ideia de 
paxira à tradução para um "código último do parentesco", que esgotaria a questão; ao contrário, constituindo uma "codificação específica da afinidade potencial", a categoria seria uma "linha de fissão do parentesco waimiri-atroari" (:96), que promove uma abertura para a mudança. Neste sentido, ele mostra que a ideia de paxira é explicada por um outro termo, parim, referente a cunhados distantes e oposto à pañ, afins próximos ou co-residentes, aproximando os primeiros ao que Viveiros de Castro denominou "relação de terceiros incluídos", "que extrapolam o âmbito do parentesco, mas são essenciais para a reprodução do socius ou da pessoa" (idem) ${ }^{3}$.

Em seguida, estes termos são colocados em paralelo aos cognatos peito, outra categoria amplamente compartilhada entre os povos guianenses que implica, de modo geral, relações assimétricas entre trocadores. Matarezio enfatiza a importância do termo no processo de integração de estranhos às comunidades caribe, sejam humanos ou não-humanos. A partir da formulação de Viveiros de Castro sobre a afinidade na Amazônia, que aponta para a predação generalizada como "modalidade prototípica da Relação nas cosmologias ameríndias”, interpreta então a iniciação masculina (babinja maryba) como processo de "assimilação (encorporação) das capacidades (afecções) de outros nãohumanos" através da ingestão da carne moqueada trazida pelos paxira, "afinižida para ser incorporada e incorporada para ser consanguiniz̧ada". Assim, e lançando uma ideia central desenvolvida adiante, afirma que "os paxira são a forma controlada, segura de relação com o diferente e seu englobamento, sua encorporação" (:103).

As seções seguintes versam sobre outras formas de relação com as diversas potências e seres do cosmos, mobilizadas no ritual e analisadas a partir da categoria apremy: traduzida pelos Waimiri-Atroaria geralmente por “donos", evoca tema já clássico na etnologia indígena. Ao examinar diferentes modalidades de donos, Matarezio enfatiza justamente a capacidade de mediação inerente à categoria, que é central para sua caracterização. Isto ressoa fortemente o caráter relacional da noção de corpo waimiri-atroari e, de modo mais amplo, o relacionalismo indissociável e estruturante da socialidade deste grupo indígena. É nesse sentido que se orienta a análise das categorias mydy iapremy, "dono da casa", chefe da aldeia ou grupo local, maryba iapremy, xamãs "donos da festa" e da palavra e kraiwa iapremy, "donos dos kraiwa" e aqueles que podem estabelecer uma relação segura com estes seres invisíveis. A partir da ideia de pessoa fractal, o caráter mediador de apremy é associado, em seguida, à multiplicidade intrínseca à constituição corpórea destes "donos”: "a relação apremy, portanto, analogamente a paxira ou parim, põe a 
pessoa, seja qual for sua escala (intrapessoal, interpessoal ou inter-grupal, nos termos de Luciani [...]), ‘em relação com'. Relação que, ao mesmo tempo, constitui a pessoa” (:121).

Chamo atenção, por fim, para dois aspectos importantes que atravessam estas seções, se conectam imediatamente à análise do ritual adiante e propiciam, durante a realização deste, o processo de apropriação das afecções desejáveis dos animais ingeridos: a importância dos cantos do maryba iapremy, que cantando as maryba dos seres que cuida, convida-os ao ritual; e o processo de moqueamento da carne que, ao retirar desta os irikwa, espíritos danosos, permite um consumo seguro, mediado pelo maryba iapremy, da carne de akaha, "carne de espírito", extremamente poderosa e perigosa. Assim, "a carne moqueada é consumida no ritual na presença dos animais que se come, ou seja, o ritual é um baquete canibal. O ritual cria esta potência na carne moqueada, que, em momentos ordinários da vida, é apenas alimento" (:115).

O terceiro e mais extenso capítulo do livro concentra "os ingredientes e a forma" segundo os quais "o socius, as relações e as pessoas" (:23) são produzidas nas festas, e especificamente no babinja maryba, que dá nome ao capítulo. Sua estrutura acompanha a própria sequência temporal da iniciação, abrindo espaços para desenvolvimentos mais prolongados e comparações etnográficas à medida que cada etapa é apresentada. Ainda que o principal substrato etnográfico na construção deste fio condutor sejam as descrições detalhadas do babinja maryba contidas na dissertação de Maria Do Vale (Universidade do Amazonas), os exemplos etnográficos mobilizados por Matarezio são muito numerosos e convergem para uma ênfase na importância decisiva que a maneira como os convidados chegam à festa tem para a conformação do caráter desta última. O processo geral de chegada constitui, assim, uma espécie de resolução pacífica do estado inicial de guerra, uma “conciliação gradual com os convidados invasores"”(:133). O autor sublinha, então, a relação fundamental de troca entre os visitantes portadores da carne de caça e os anfitriões com suas bebidas: "a predação dos animais caçados é a condição da troca ritual de carne moqueada por mingau. A caça é o produto da predação que será incorporada ao mundo social [...], ou melhor, como tentarei mostrar, produto a ser encorporado pelos babinja [iniciandos]” (:136).

Se o "primeiro movimento" do ritual de iniciação é caracterizado, em suma, pela afinização dos inimigos, ele consiste apenas no início do karaweri maryba, parte inicial que antecede o açoitamento dos neófitos, o behe, e sua possível confirmação. Neste momento, a referência do autor é o karaweri, nome de uma planta e da mistura de barro utilizada na pintura dos participantes da festa. Acompanhando seu modo de produção, Matarezio 
enfatiza a associação entre o preparado e o sangue que caracteriza os verdadeiros kinja e a "sua função de depurativo do veneno" (:141) inoculado pelas formigas no iniciando, realizada através do conjunto de "remédios" contra dores ('kamca) produzidas pelo veneno ou feitiçaria (mas'ki) que compõe o karaweri. Em seguida, e a partir de uma formulação de Lévi-Strauss a respeito do ritual, associa o cesto matyty, dado pela cobra-grande Xiriminja aos antigos e que é sua própria pele, à inserção no "mundo dos sonhos". "Momento chave do ritual, a colocação do cesto na cabeça do neófito, poderia ser interpretada [como] uma passagem do mundo da descontinuidade para um mundo da continuidade, 'mundo dos sonhos' nas palavras de Do Vale [...], mundo em que as transformações são possíveis como as transformações que ocorrem no mito" (:143). Torna-se possível, assim, a produção de corpos específicos e a fabricação de uma nova pele para o neófito através das potências e substâncias mobilizadas no ritual: "ao por o matyty na cabeça ou as carnes moqueadas dentro dele [as quais somente os neófitos irão ingerir], evoca-se a potência transformadora do Xiriminja, veste-se sua pele" (:146).

Em seguida, o autor estabelece um paralelo entre a primeira transformação do xamã durante o ritual que, sendo eremy-onça e lutando contra vespas, se deixa picar para tornar-se um grande caçador, e os iniciandos que, neste momento, são levados às picadas das formigas tucandeiras iky. Articulando-o com aspectos das narrativas míticas waimiri-atroari, Matarezio mostra que, ao serem inoculados com o veneno das formigas, seres altamente sociáveis, os neófitos são afetados pela potência predadora destas sem se tornarem caçadores solitários, como a onça. O texto prossegue com a entoação dos próximos cantos (maryba) que fazem referência a diversos animais, plantas e outros seres do cosmos, acompanhados de outras transformações xamanísticas, fundamentais no processo de captura de qualidades em curso. A notável atenção às qualidades sensíveis mobilizadas na análise do ritual e dos mitos guianenses relacionados evidencia uma inspiração lévi-straussiana - que, como vimos acima, se mostra presente em outros aspectos deste trabalho - e produz um enriquecimento notável do texto quando em diálogo com as variadas referências às descrições oriundas da zoologia e botânica, sendo justamente aí onde muitas das interessantes hipóteses lançadas a respeito do bahinja maryba encontram parte de sua sustentação.

Durante o longo percurso do ritual, acompanhado detalhadamente por Matarezio, o papel do veneno mais uma vez se revela fundamental: elemento ambíguo que reduz a distância entre natureza e cultura, encerra em si uma capacidade produtora, mas ao mesmo tempo perigosa. "No ritual, o menino inoculado com o veneno para se tornar bom 
caçador, tem uma máxima aproximação da natureza, uma 'máxima animalização' de seu corpo; mas ao findar o ritual, precisa voltar ao pólo da cultura, o veneno (ou o sangue envenenado) deve ser eliminado" (:182-183). Durante o complexo processo de captura em operação no ritual, é preciso realizar, portanto, uma alternância precisa e cuidadosa entre momentos nos quais "potências predatórias são infundidas nos neófitos" e outros onde “a domesticação e a alimentação são postas em destaque” (:207). Voltamos ao eremy-onça, onde o motivo central já está dado, reaparecendo de maneiras diversas posteriormente: o sucesso na caça vinculado à potência predatória oriunda da inoculação do veneno. O açoitamento, behe, momento máximo do ritual de passagem, promove, nos mostra Matarezio, a retirada de seu excesso, negação parcial da toxicidade necessária à conformação dos verdadeiros kinja.

Uma das hipóteses mais interessantes e enfatizadas pelo autor ao longo do capítulo é tecida em relação a estas conclusões: refiro-me à analogia, expressa de maneiras variadas pelos próprios Waimiri-Atroari, entre o processo de produção da tapioca e o processo de iniciação dos jovens indígenas. A comparação é elaborada por Matarezio em múltiplos sentidos, e adquire sua complexidade na medida em que um exame linguístico sobre os termos utilizados para se referir ao processo e aos produtos diversos da mandioca se alia à evocação de ricas descrições do preparo da mandioca brava, planta venenosa que, após purificada, se tornará a tapioca. Este produto fundamental para a vida dos Waimiri-Atroari precisa passar pelo tipiti, instrumento purificador que "marca a passagem de uma matéria selvagem e tóxica ao alimento, domesticado, desintoxicado" (:171), assim como os neófitos passarão pelo açoitamento behe. Ressoando as conclusões de Viveiros de Castro, o autor afirma que "é o padrão da predação do exterior o que norteia esta composição das pessoas do grupo" (idem), e que guia, portanto, o processo de extração da toxicidade e de canibalização constituinte da cultura.

Em suas considerações finais, Matarezio coloca sua análise do ritual à luz da teoria lévi-straussiana da troca, do perspectivismo ameríndio conforme Viveiros de Castro e da teoria da pessoa fractal, elaborada por Roy Wagner e Jose Luciani, pretendendo "refletir sobre a troca de 'pessoas' em escalas múltiplas, ou, em outros termos, a troca de perspectivas" (:219). Nesse sentido, o autor traça um paralelo entre o inimigo cativo de guerra tupinambá e os paxira waimiri-atroari que trazem a carne do ritual babinja maryba, mostrando que ambos os casos "ternarizam a oposição entre consanguíneos e afins, são o termo médio e mediador entre interior e exterior, cognatos e inimigos, co-residentes e estrangeiros [...], o Eu e o Outro" (:229). Através dos afins, os meninos iniciandos podem 
ingerir partes dos corpos de animais e plantas, perspectivas outras; mas são também os próprios afins transacionáveis, pessoas que se tornam "parte do próprio neófito", compondo o "feixe de relações que integram os kinja adultos" (:28).

A encorporação do Outro pelo Eu entre os meninos waimiri-atroari passa, portanto, pela iniciação estabelecida através das relações com os paxira, os "afins por excelência" e é imprescindível para a perpetuação de relações, produção de novas pessoas e reprodução do socius. Ao encontro de Rivière, é possível afirmar agora que nas Guianas "não existe uma distinção entre a reprodução da sociedade e a reprodução da pessoa" (:235): Matarezio reforça, assim, o papel da alteridade como operador de abertura fundamental dos grupos locais guianenses, os quais, em uma feliz apropriação da imagem lévi-straussiana sobre a relação entre família e sociedade, são apresentados como verdadeiras paragens ao longo do curso do socius. Em suas palavras,

as paradas são uma espécie de negação da marcha da viagem, no entanto, são fundamentais para se "ganhar fôlego". A sociedade, ou melhor, como se tratam de relações e não de grupos reificados, a socialidade, portanto, se opõe a existência isolada dos grupos locais, estes só existem em suas relações com outros grupos locais, e a totalidade dos grupos locais em relação aos inimigos de fora (ibidem).

O livro, por fim, ainda contém um posfácio de Stephen Baines e apresenta, em anexo, algumas das narrativas míticas waimiri-atroari mencionadas ao longo da obra. Ritual e Pessoa entre os Waimiri-Atroari é certamente de uma contribuição notável ao campo etnológico, abordando de maneira exemplar e cuidadosa questões clássicas da disciplina e, ao mesmo tempo, nutrindo um diálogo já comprovadamente enriquecedor entre a etnologia americanista e trabalhos e modelos melanesistas, como é o casos das referências a Roy Wagner. Sem pretender encerrar discussões, as diversas e interessantes hipóteses lançadas por Matarezio e o caráter fundamentalmente comparativo do livro instigam à experimentação e à pesquisa etnológica que busque diálogos cada vez mais amplos, ainda que não ausentes de desafios e dificuldades.

\footnotetext{
${ }^{1}$ O Programa Waimiri-Atroari (PWA) consiste em uma "instituição que gerencia os recursos repassados pela Eletronorte aos índios Waimiri Atroari” (:24), referentes à compensação de danos causados pela inundação provocada pela construção da Hidrelétrica de Balbina (ver mais em :51).

2 Matarezio segue as indicações e desenvolvimentos de José Kelly Luciani a respeito da produtividade de
} 
aproximações entre conceitos desenvolvidos no campo etnográfico melanésio e amazônico, aproximações que emergem em uma série de momentos da obra apreciada e, como observa Matarezio (:225), evidenciam certas diferenças das noções de pessoa presentes nestas regiões. Noto apenas - e agradeço Leonardo Braga pela lembrança - que a pertinência e os limites destas operações de aproximação e comparação são temas de debates atuais da etnologia - ver, por exemplo, Saez (2003).

3 Vale retomar aqui o comentário bastante elucidativo de Rivière sobre a noção de "terceiro incluído" formulada por Viveiros de Castro: "This notion refers to the widely reported presence in Lowland South America of roles mainly external to kinship: formal friends, trading partners, and captives [...]. They provide the dynamism within the concentric world by mediating the same and other, the inside and outside, friend and enemy, living and dead. Above all, perhaps, it is the potential or classificatory affine that fulfils this role of thirdness, and why it is that affinitiy, which suggests something to do with relations through marriage, has also to do with the fact or fantasy of cannibalism" (1993: 512).

\title{
Referências bibliográficas
}

\author{
RIVIÈRE, Peter
}

1993 “The amerindianization of Descent and Affinity”. L'Homme, La remonté de l'Amazone, tome 33, n. 126-128: 507-516.

SAEZ, Oscar Calavia

2003 “Melazônia e suas Sombras". Revista de Estudos Feministas, vol. 11, n.1: 316-318.

Viveiros De CASTRO, Eduardo

1996 "Os pronomes cosmológicos e o perspectivismo ameríndio". Mana, vol. 2, n.2: $115-144$. 